\section{Examen de spécialiste en vue de l'obtention du titre de spécialiste FMH en urologie}

Conformément au programme de formation postgraduée entrée en vigueur le $1^{\mathrm{er}}$ janvier 1995 et révisé le $1^{\text {er }}$ juillet 1997, la participation à l'examen de spécialiste est requise pour les candidats à l'obtention du titre de spécialiste FMH en urologie, qui n'avaient pas encore terminé leur formation postgraduée en urologie le 31 décembre 1995 (opérations incluses).

\section{Examen de base en chirurgie}

Premier examen théorique écrit (examen de base) de l'Union des sociétés chirurgicales suisses. Examen à choix multiple portant sur les connaissances générales en chirurgie (connaissances de base).

Il est recommandé au candidat de passer l'examen de base en chirurgie après la deuxième année de formation postgraduée en chirurgie générale.

Lieux: Hôpital de l'Ile, Berne/CHUV, Lausanne

Date: Samedi 11 novembre 2000

Taxe d'examen: La SSC prélève une participation aux frais de fr. 250.--

Renseignements et inscription:

Secrétariat de la Clinique de chirurgie,

Hôpital cantonal, 9007 St-Gall, Tél. 0714941312

Délai d'inscription: le 30 juin 2000

\section{Examen de l'European Board of Urology (EBU)}

Second examen théorique écrit portant sur l'urologie. Examen à choix multiple organisé dans le cadre de l'EBU dans la langue nationale choisie par le candidat.
L'évaluation pour l'obtention du titre de spécialiste FMH est basée sur des critères particuliers définis par la commission de formation postgraduée de la SSU.

Il est recommandé au candidat de passer l'examen de l'EBU au plus tôt durant la dernière année de la formation postgraduée réglementaire.

Lieu: Clinique d'urologie de l'Hôpital cantonal de Lucerne (salle de réunion $2^{\mathrm{e}}$ étage)

Date: Samedi 25 novembre 2000, de $13 \mathrm{~h} 30$ à $17 \mathrm{~h} 00$

Taxe d'examen: Une taxe d'examen de 325 EURO est à verser directement à l'EBU.

Renseignements et inscription:

EBU Office of Education, PO Box 25285,

NL-3001 HG Rotterdam, tél. +31 10436 6665,

fax +31 10436 6669, e-mail ebu@ebu.com,

web: www.ebu.com

Délai d'inscription: le 15 juillet 2000

\section{Examen pratique oral}

Se déroule sur le lieu même de formation postgraduée du candidat. C'est la commission d'examen élue par la SSU qui est chargée d'organiser cette épreuve.

Seuls les candidats ayant effectués toutes les opérations requises par le catalogue en question et réussi l'examen de base en chirurgie et l'examen théorique écrit de l'EBU seront admis à l'examen pratique oral.

Lieu et date: Sur convocation de la commission d'examen de la SSU.

Taxe d'examen: La SSU prélève une participation aux frais de fr. 800.-.

Renseignements et inscription:

Secrétariat du Service d'urologie, BH 10, CHUV, 1011 Lausanne, tél. 0213142981

Délai d'inscription: le 31 juillet 2000 ou le 31 janvier 2001 